\title{
Minimum intervention dentistry explored in Manchester
}

The $B D J$ hosted the first minimum intervention interactive panel session at the British Dental Conference and Exhibition in

Manchester in May.

Led by Dr Stephen Hancocks OBE, the BDJ's Editor-in-Chief, and Professor Avijit Banerjee, Professor of Cariology \& Operative Dentistry at King's College London Dental
Institute, the panel explored the clinical, business, behavioural and medico-legal aspects of minimum intervention oral healthcare delivery. Panel experts Drs Bhupinder Dawett, Fariha Hussain, Len D'Cruz and Professor Tim Newton gave a breadth of insight into how the MI approach can be successfully incorporated in general

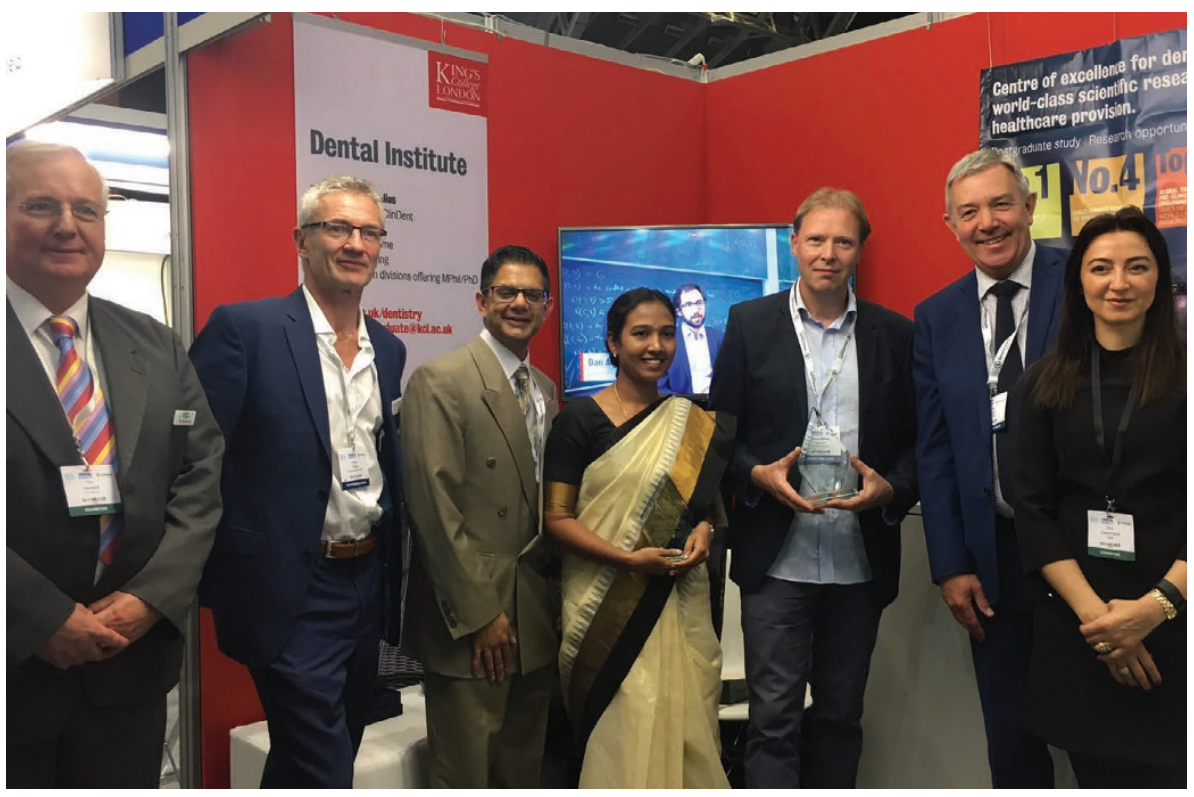

From left to right: Mr Tim Horwood (GCUK), Dr Henry Clover (CDO, Simplyhealth Professionals), Prof Avijit Banerjee (Programme Director, MSc AMID, KCLDI), Dr Thillai Viswapurna (Patricia Santos AMID Scholarship merit winner, 2017), Dr Stuart Grundy (Patricia Santos AMID Scholarship merit winner, 2017), Dr Stephen Hancocks (Editor-inChief, $B D J)$ and Dr Eva Castro-Perea (Oral B) dental practice, to benefit patients, dentists and the whole oral healthcare team. Highly active audience input generated meaningful data, discussions and ideas for case planning and practical implementation.

Professor Banerjee said: 'With MI dentistry now clearly on the professional, public, industry and government radar, this session helped hardworking oral healthcare practitioners to rationalise MI clinical decisions. Knowledge is expanding along with the scientific and clinical evidence base for the MI approach to patient-focused, team-delivered oral healthcare, and it is clear that all stakeholders must now engage with the process'.

After the session, two second year postgraduate students from Professor Banerjee's Advanced Minimum Intervention Dentistry (AMID) flexible-learning MSc course, Dr Thillai Viswapurna and Dr Stuart Grundy, received prestigious Patricia Santos Memorial Scholarship prizes for clinical academic excellence and celebrated with the industry partner sponsors, Simplyhealth Professionals, Oral-B and GC UK.

A themed issue on the topic of minimum intervention dentistry, guest-edited and part-authored by Professor Banerjee, will be published in the $B D J$ this summer.

www.kcl.ac.uk/midentistry

\section{Plymouth and New York exchange ideas}

Three educators and clinicians from Plymouth University Peninsula School of Dentistry have visited New York University College of Dentistry to exchange ideas and experiences of inter-professional learning - where students training to be dentists do so side-by-side with other dental professional students (such as dental nurses, dental therapists and hygienists) and other healthcare professionals such as nurses.

Jane Collingwood and Clare McIlwaine went to New York University College of Dentistry thanks to a Santander Internationalisation Scholarship, a grant awarded to help build collaborative relationships for research, skill sharing and career development among Santander universities.

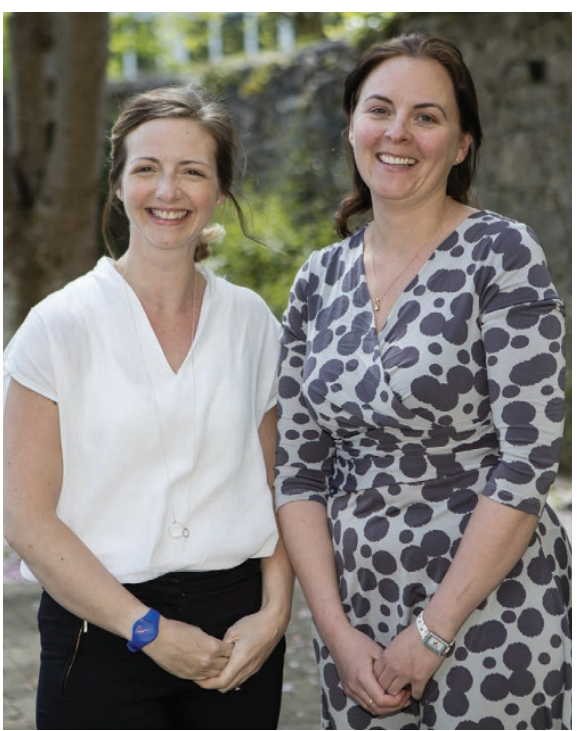

Clare Mcllwaine and Jane Collingwood
Their colleague Louise Belfield travelled separately and joined Jane and Clare at NYU to complete the multi-professional team and gained experience of integrating clinical and basic science education among multiple undergraduate programmes.

Both the University of Plymouth and New York University have renowned reputations for inter-professional learning. Plymouth leads the way in a completely new and innovative programme which trains future dentists and dental therapists and hygienists side-by-side from the very start of their programmes. Jane and Clare shared experiences and learned best practice with their colleagues in New York. They are hopeful that this visit will lead to joint projects in the future. 